\title{
Maternal Inhalation of Humidifier Disinfectant Biocide Aerosol Particles, Polyhexamethylene Guanidine Phosphate, Induces Adverse Postnatal Development in Rat Offspring
}

Jinsoo Lee

Korea Institute of Toxicology

Seong-Jin Choi

Korea Environment Corporation

Ji-Seong Jeong

Korea Institute of Toxicology

Sang Yun Kim

Korea Institute of Toxicology

Seung-Jin Lee

Korea Institute of Toxicology

Sang-Ki Baek

Korea Institute of Toxicology

Sang-Hyub Lee

Korea Environment Corporation

Woojin Kim

Korea Institute of Toxicology

Jae-Woo Cho

Korea Institute of Toxicology

Eun Mi Koh

Korea Institute of Toxicology

Kyuhong Lee

Korea Institute of Toxicology

Eun Ju Jeong

Korea Institute of Toxicology

Sang-Yoon Nam

Chungbuk National University College of Veterinary Medicine

Wook-Joon Yu ( $\nabla$ yuwj@kitox.re.kr)

Korea Institute of Toxicology

Research 
Keywords: developmental toxicity, maternal exposure, hazard identification, extended one-generation reproductive toxicity study (EOGRTS)

Posted Date: December 22nd, 2020

DOI: https://doi.org/10.21203/rs.3.rs-131830/v1

License: (c) (i) This work is licensed under a Creative Commons Attribution 4.0 International License. Read Full License 


\section{Abstract}

Background: Inhalation exposure to polyhexamethylene guanidine phosphate (PHMG-P), one of the primary biocides used in humidifier disinfectants, caused a fatal pulmonary disease in Korea. Pregnant women were also exposed to PHMG-P, and subsequent studies showed that PHMG-P inhalation adversely affects their health and prenatal development. However, the postnatal developmental effects on prenatally PHMG-P-exposed offspring have not yet been investigated. Therefore, in this study, we examined the postnatal developmental effects of offspring with prenatally PHMG-P exposure. PHMG-P aerosol particles were exposed to pregnant rats via inhalation during pregnancy at concentrations of $0,0.14,1.60$, and $3.20 \mathrm{mg} / \mathrm{m}^{3}$, and general and reproductive functions of pregnant rats were also investigated. After parturition, comprehensive postnatal development of offspring was investigated, including general systemic health, reproduction, and development.

Results: At $3.20 \mathrm{mg} / \mathrm{m}^{3}$, increased perinatal death and decreased viability index (postnatal survival of offspring between birth and postnatal day 4) were observed. In addition, offspring had lower body weight at birth that persisted throughout the study. PHMG-P-exposed pregnant rats had severe systemic toxicities and increased gestation length. At $1.60 \mathrm{mg} / \mathrm{m}^{3}$, a decreased viability index was also observed with systemic toxicities of PHMGP-exposed pregnant rats.

Conclusion: As a result, maternal inhalation exposure of PHMG-P aerosol particles during pregnancy induced adverse postnatal development in rat offspring and they were observed with systemic toxicities of their maternal animals. The results of this study could be used for risk assessment of postnatal development of prenatally PHMG-P-exposed offspring as well as reproductive and developmental effects on females with PHMG-P inhalation exposure during pregnancy.

\section{Introduction}

Polyhexamethylene guanidine phosphate (PHMG-P) is part of the polymeric guanidine family and is used as a biocide in household products [1]. PHMG-P-containing cleaning products, wet wipes, shampoos, and detergents are widely used in our real life [2, 3]. PHMG-P is known to disturb the main component of the bacterial membrane, but it is considered to be relatively less toxic to humans $[4,5]$. PHMG-P was also used as a humidifier disinfectant biocide in Korea because of its water-soluble and anti-microbial growth properties. However, PHMG-P used in this formulation leads to unintentional PHMG-P inhalation exposure to humans, causing an unexpected massive fatal pulmonary disease in Korea.

The fatal pulmonary disease was first reported to the Korea Centers for Disease Control and Prevention (KCDC) by a tertiary university hospital in April 2011. The patients had severe pneumonia without fever and did not respond to antiviral or immunosuppressive agents [6, 7]. A hospital-based case-control study to search for potential causes of this fatal pulmonary disease concluded that humidifier disinfectants have a significant relevance $[8,9]$. Since this first report, the number of confirmed deaths related to humidifier disinfectant-induced pulmonary disease was 209 as of July 2020, and the investigation is in progress [10]. In particular, several commercial biocides were revealed to be related with fatal pulmonary disease through an additional investigation, and PHMG$P$ was considered to be the most frequently used biocide among patients with fatal pulmonary disease $[11,12$, 13] 
After the outbreak of this massive fatal pulmonary disease, a number of studies have been performed with PHMG-P to thoroughly investigate its toxicity. An inhalation toxicity study in rats demonstrated that repeated PHMG-P inhalation exposure leads to pulmonary toxicity similar to that occurring in humans [14]. In addition, several studies confirmed that this pulmonary toxicity is caused by inflammatory and fibrotic responses $[15,16$, 17]. Pregnant women and their offspring have also been exposed to PHMG-P $[18,19]$, and our previous studies in rats demonstrated that repeated exposure to PHMG-P induces toxicity in pregnant rats and in their offspring at a very early life stage [20, 21]. However, the potential effects of prenatal PHMG-P exposure on the postnatal development of offspring have not been investigated.

Therefore, in the present study, we investigated the postnatal development of offspring with prenatal PHMG-P exposure in utero. A cross-fostering method in which offspring from prenatally PHMG-P-exposed dams were transferred to non-exposed surrogate mothers was used to minimize the secondary effects of severe maternal toxicities that might have an impact on postnatal development of offspring during lactation. In addition, the study design for postnatal development of offspring referred to the extended one-generation reproductive toxicity study from the Organization for Economic Co-operation and Development (OECD) guideline for the testing of chemicals (OECD testing guideline 443) to extensively investigate its potential toxicities [22]. Offspring were assigned to each cohort after weaning, and then postnatal development, including general systemic toxicity, reproductive toxicity, developmental neurotoxicity, developmental immunotoxicity and developmental respiratory toxicity, were investigated.

\section{Materials And Methods}

\subsection{Animals and Environmental Conditions}

Sprague-Dawley (SD) female rats (10-week-old, Orient Bio, Republic of Korea) were used after a 5-day acclimation period. Male rats of the same strain were used for mating, and then mating-proven females were selected to use as females with PHMG-P inhalation exposure during pregnancy or non-exposed surrogate mothers for the crossfostering method. All animals were housed in stainless-steel or polysulfone cages (with sterilized aspen bedding for pregnant and lactating females) under controlled conditions. Temperature, humidity, air ventilation, and artificial lighting were maintained at 19 to $25^{\circ} \mathrm{C}, 30-70 \%, 10$ to 20 changes/hour, with a 12-hour cycle.

Commercial rat diet (gamma-ray-irradiated, PMI Nutrition International, USA) and tap water (filtered and ultraviolet light-irradiated) were provided ad libitum.

All animal procedures were performed in two different facilities in consideration of experimental equipment and expertise. Animal procedures from acclimation to inhalation exposure were performed at the Jeonbuk campus of the Korea Institute of Toxicology (KIT). After completion of the final inhalation exposure, females were moved to the Daejeon campus of KIT (approximately one-hour by car) under controlled environmental conditions. All remaining animal procedures were performed in the Daejeon campus, with the exception of cohort 4 F1 offspring that were moved back to the Jeonbuk campus under controlled environmental conditions after weaning.

Offspring was moved to evaluate pulmonary function and performed micro-computed tomography (CT) scan of the lungs.

The animal study procedures were approved by the KIT Institutional Animal Care and Use Committee (Approval no. 1801-0045) and followed the domestic laws and the National Research Council guide for laboratory animals 
[23]. KIT has been approved by the Association for Assessment and Accreditation of Laboratory Animal Care International for all animal procedures in its facility.

\subsection{PHMG-P and Inhalation Exposure}

PHMG-P (CAS No. 89697-78-9) was obtained from SK chemicals (Republic of Korea). PHMG-P was dissolved in sterilized distilled water (Dai Han Pharm, Republic of Korea) for animal expose. Mating-proven females assigned to the PHMG-P inhalation exposure during pregnancy group were exposed to PHMG-P in whole-body inhalation chambers (HCT, Republic of Korea) as previously described and following OECD testing guidelines [21, 24]. Briefly, aerosolized PHMG-P was diluted with filtered clean air for exposure at target concentrations of $0,0.14,1.60$, and $3.20 \mathrm{mg} / \mathrm{m}^{3}$. PHMG-P exposure of pregnant rats was performed for $6 \mathrm{~h} /$ day (from implantation to nearly parturition; from gestation day 6 through day 20, inclusive). The atmospheric exposure condition (every hour), actual exposure concentration (three times per day), and particle size distribution (once per week) were regularly monitored during the study period.

PHMG-P inhalation exposure concentration was determined based on epidemiological investigations in humans and our previous study [21, 25]. The high concentration, $3.20 \mathrm{mg} / \mathrm{m}^{3}$, was calculated from actual exposure concentrations to pregnant women considering the physiological differences between human and rats, including respiratory rate, respiratory vital capacity, body weight, species difference, and exposure duration. The middle concentration, $1.60 \mathrm{mg} / \mathrm{m}^{3}$, was selected based on the results of our previous inhalation embryo-fetal development study, in which significantly decreased body weight gain (82\% of control) was observed during pregnancy at this concentration level of PHMG-P-exposed females. The low concentration, $0.14 \mathrm{mg} / \mathrm{m}^{3}$, was selected assuming no PHMG-P inhalation exposure-related toxicities during the study. In addition, control animals were exposed to filtered clean air.

\subsection{Experimental Design}

A brief graphical representation of the study design is presented in Fig. 1. Mating-proven females were divided into PHMG-P-exposed F0 females and non-exposed surrogate mothers. PHMG-P-exposed F0 females were distributed into four groups (22 or 24 females per group) based on body weight at gestation day (GD) 0 to have similar group means for body weight. All PHMG-P-exposed F0 females were exposed in whole-body inhalation chambers ( 6 h per day) from GD 6 to 20, and then were allowed to have their litters. On parturition completion day, offspring from PHMG-P-exposed FO females were transferred to healthy non-exposed surrogate mothers to observe the postnatal development of offspring during lactation. Our previous results revealed that PHMG-P inhalation exposure during pregnancy caused severe systemic toxicity to dams [21]. Therefore, this crossfostering method was performed to minimize the effects of maternal systemic health status on postnatal development of prenatally PHMG-P-exposed offspring. Offspring from non-exposed surrogate mothers were humanely sacrificed just before the cross-fostering. On postnatal day (PND) 4, the litter size was randomly adjusted to 10 offspring (five males and five females) per litter, if possible. On PND 21, the F1 offspring were weaned and randomly assigned to investigate the postnatal development as the following cohorts: general systemic toxicity (cohort 1A), reproductive toxicity (cohort 1B), developmental neurotoxicity with adult animals (cohort 2A), developmental neurotoxicity with young animals (cohort 2B), developmental immunotoxicity (cohort 3 ), and developmental respiratory toxicity (cohort 4). One male and one female F1 offspring from each litter were randomly selected for each group in each cohort, if possible. 


\subsection{FO Maternal Evaluation}

During the gestation period, PHMG-P-exposed F0 females were observed twice daily for mortality or morbidity. Individual clinical signs were observed twice daily and detailed clinical examinations were performed approximately once weekly to detect abnormal signs in general health. Body weight and food consumption were measured on GD $0,6,9,12,15,18$, and 20 . On parturition day, the number of live/dead offspring as well as characteristics such as sex, body weight, external examinations, and gestation length were recorded, and then offspring were transferred to non-exposed surrogate mothers. All PHMG-P-exposed F0 females were humanely sacrificed after the cross-fostering, and then macroscopic observation was performed. The number of implantation sites in the uterine horn was also counted during necropsy to observe perinatal death.

During the lactation period, non-exposed surrogate mothers were observed twice daily for mortality or morbidity. Individual clinical signs were observed once daily and detailed clinical examinations were observed approximately once weekly. Body weight and food consumption were measured on lactation day (LD) $0,4,7,14$, and 21. All non-exposed surrogate mothers were humanely sacrificed after cohort assignment on LD 21, and then macroscopic observation was performed.

\subsection{Evaluation of Postnatal Development of F1 Offspring 2.5.1. F1 offspring evaluation during lactation}

F1 offspring were observed once daily for survival, and all deaths were recorded during the lactation period (from beginning of the parturition day to cohort assignment). The following parameters were calculated based on the survival record of offspring: mean live litter size (PND 0, 4, and 21), postnatal survival between birth and PND 4 (viability index), and postnatal survival between PND 4 and 21 (weaning index). Individual clinical signs were also observed once daily for any changes in appearance or behavior. Body weight of each individual offspring was measured on PND 0, 4, 7, 14, and 21. Anogenital distance of each individual offspring was measured on PND 4 and nipple retention of each male offspring was observed on PND 12. After cohort assignment on PND 21, all offspring that were not assigned were humanely sacrificed with carbon dioxide, and then macroscopic observation was performed. Organ weights (brain, spleen, thymus, and lungs) were measured and whole blood was collected from 10 offspring/litter/sex/group among unassigned offspring. Serum levels of thyroxine (T4; MyBioSource, USA) and thyroid-stimulating hormone (TSH; Elabscience, USA) were measured from collected whole blood on PND 21 using enzyme-linked immunosorbent assays according to the manufacturer's instructions.

\subsubsection{General systemic toxicity (cohort 1A)}

In-life observation, including mortality, general clinical signs, detailed clinical signs, body weight, food consumption, sexual maturity, first estrus day, and estrus cycle examination were observed during the study. Mortality and general clinical signs were observed twice daily, and detailed clinical signs, body weight, and food consumption were monitored once weekly. Sexual maturation was monitored on the day of vaginal opening in females and preputial separation in males from PND 26 and 36 onwards, respectively. First estrus day was determined from females with vaginal opening. In addition, estrus cycle examinations, including length and regularity, were monitored for a period of two weeks commencing at approximately PND 77. 
Terminal observations, including macroscopic observation, clinical pathology, organ weights, microscopic observation, sperm analysis, lymphoid analysis, and thyroid hormone analysis (T4 and TSH) were performed during the study. At scheduled termination times (at approximately 13 weeks of age), all animals were euthanized with isoflurane, and blood samples were collected from 10 animals/sex/group for clinical pathology and thyroid hormone analysis. Clinical pathology included hematology, coagulation, and clinical chemistry, which were evaluated analyzed using the ADVIA2120i hematology analyzer (Siemens, USA), ACL 9000 coagulation analyzer (Instrumentation Laboratory, USA), and 200 FR NEO chemistry analyzer (Toshiba, Japan), respectively.

Macroscopic observation was performed on all animals following termination. The weights of the following trimmed organs was determined: brain, kidneys, pituitary gland, adrenal glands, liver, testes, spleen, epididymides, heart, lungs, thymus, thyroids with parathyroids after fixation, salivary glands, uterus with cervix, seminal vesicles with coagulating gland, prostate, and ovaries. The relative organ weight was also calculated based on the terminal body weight. Microscopic observation of the following fixed organs was performed: abnormal lesions, ovaries, adrenal glands, prostate, pituitary gland, brain, rectum, cecum, sciatic nerve, colon, seminal vesicle with coagulation gland, duodenum, skeletal muscle, epididymides, spinal cord (cervical, thoracic, and lumbar), esophagus, spleen, eyes with optic nerve, sternum with marrow, femur with marrow (F-T joint), stomach, heart, testes, ileum, thymus, jejunum, thyroids with parathyroids, kidneys, trachea, liver, urinary bladder, lungs with bronchi, uterus with cervix, mammary gland, vagina, mandibular lymph node, mesenteric lymph node, and vas deferens. Microscopic observation was performed from vehicle control and high concentration groups, and any organs with macroscopic abnormalities were also examined.

Sperm analysis, including motility, morphology, and number, was performed on all male animals following termination. The left caudal epididymis of each male was used for sperm motility evaluation using the computer assisted sperm analysis method in Hamilton Thorne IVOS (Hamilton Thorne Research, USA). Sperm morphology was evaluated from 200 sperms of each male using a light microscope after eosin staining. In addition, sperm number was counted from the left testis and epididymis using a hemocytometer after homogenization. Lymphoid analysis was performed with collected spleen from 10 animals/sex/group at terminal sacrifice. A single-cell suspension of splenocytes (approximately $3 \times 10^{6}$ cells $/ \mathrm{mL}$ ) in stain buffer (BD biosciences, USA) was prepared, stained, fixed, and analyzed using a flow cytometer (FACS Calibur, BD biosciences, USA). The percentage of each lymphocyte subset was determined using the Cell Quest Pro software (BD biosciences, USA).

\subsubsection{Reproductive toxicity (cohort 1B)}

In-life observation, including mortality, general clinical signs, detailed clinical signs, body weight, food consumption, sexual maturity, fertility indices, precoital time (the number of days for animals were determined to mate), and reproductive and littering findings were observed during the study. After parturition, F2 offspring mortality, general clinical signs, body weight, anogenital distance, and nipple retention during the lactation period were observed. For cohort 1B F1 offspring, mortality and general clinical signs were observed twice daily, and detailed clinical signs, body weight, and food consumption were monitored once weekly. Sexual maturation was monitored on the day of vaginal opening in females and preputial separation in males from PND 26 and 36 onwards, respectively. Precoital time and fertility data were calculated based on the mating results during the mating period. Each female was mated with a single male of the same concentration group at approximately 14 weeks of age. Mating was determined by sperm observed in vaginal smear or a copulatory plug observed in situ, and this was considered GD 0 . Reproductive and littering findings were calculated based on the parturition results. The progress and completion of parturition was observed, and then the number of live/dead offspring and 
characteristics such as sex, body weight, external examinations, and gestation length were recorded. After parturition, F2 offspring were observed once daily for mortality and general clinical sings during the lactation period. Body weight of each F2 offspring was measured on PND 0, 4, 7, 14, and 21. A litter size with more than eight offspring was reduced to eight (four males and four females) by random culling on PND 4. Anogenital distance of each F2 offspring was measured on PND, 4 and nipple retention of each F2 male offspring was observed on PND 12.

Terminal observations, including macroscopic observation and organ weight determinations were performed for all cohort 1B F1 offspring. At scheduled termination (after confirmation of parturition results for males and LD 21 for females), all cohort 1B F1 offspring were euthanized with carbon dioxide, and then macroscopic observation was performed on all animals. In addition, the number of implantation sites was counted for all females. The weight of the following trimmed organs was determined: adrenal glands, testes, seminal vesicles with coagulating gland, epididymides, ovaries, lung, thyroid with parathyroid after fixation, uterus with cervix, and prostate. F2 offspring were humanely sacrificed with carbon dioxide on PND 21, and macroscopic observation was performed. Organ weights (brain, spleen, thymus, and lungs) were determined and whole blood was collected from 10 offspring/litter/sex/group. T4 and TSH levels in serum were measured from collected whole blood on PND 21.

\subsubsection{Developmental neurotoxicity (adult animals, cohort 2A)}

In-life observation, including mortality, general clinical signs, detailed clinical signs, body weight, food consumption, sexual maturity, auditory startle response, functional observation battery (FOB), and motor activity were observed during the study. Mortality and general clinical signs were observed twice daily, and detailed clinical signs, body weight, and food consumption were monitored once weekly. Sexual maturation was monitored on the day of vaginal opening in females and preputial separation in males from PND 26 and 36 onwards, respectively. Acoustic startle response, the movement of the ears in response to sound (approximately $90 \mathrm{~dB}$ ), was observed on PND 23. FOB and motor activity were examined on PND 63 as described previously [26, 27].

Terminal observations, including macroscopic observation, brain weight determination, and neurohistopathology were performed for all cohort 2A F1 offspring. At scheduled termination (at approximately 11 weeks of age), all cohort 2A F1 offspring were euthanized with isoflurane, and then perfusion fixation was performed for neurohistopathological examination. Macroscopic observation was performed, and then brain weight was measured. Neurohistopathological examination of the following fixed organs was performed: brain (including olfactory bulbs, cerebral cortex, hippocampus, basal ganglia, thalamus, hypothalamus, mid-brain including tectum, tegmentum, cerebral peduncles, brain-stem, and cerebellum), spinal cord (with dorsal and ventral root fibers), skeletal muscle, eyes (retina and optic nerve), proximal sciatic nerve, tibial nerve calf muscle branches, and proximal tibial nerve (at the knee). Neurohistopathological examination was performed based on several published documents [28, 29,30,31].

\subsubsection{Developmental neurotoxicity (young animals, cohort 2B)}

F1 offspring on cohort 2B were euthanized with isoflurane on PND 21, and then perfusion fixation was performed for neurohistopathological examination. Macroscopic observation was performed, and then brain weight was measured. Neurohistopathological examination of the fixed brain (including olfactory bulbs, cerebral cortex, 
hippocampus, basal ganglia, thalamus, hypothalamus, mid-brain including tectum, tegmentum, cerebral peduncles, brain-stem, and cerebellum) as cohort 2A animals were performed.

\subsubsection{Developmental immunotoxicity (cohort 3)}

In-life observation, including mortality, general clinical signs, detailed clinical signs, body weight, food consumption, sexual maturity, and T-cell dependent immunosuppressive response were performed during the study. Mortality and general clinical signs were observed twice daily, and detailed clinical signs, body weight, and food consumption were monitored once weekly. Sexual maturation was monitored on the day of vaginal opening in females and preputial separation in males from PND 26 and 36 onwards, respectively. For the T-cell dependent immunosuppressive response, keyhole limpet hemocyanin (KLH, Sigma, USA) was intravenously injected (300 $\mu \mathrm{g} / 2 \mathrm{~mL} / \mathrm{kg}$ ) to all cohort $3 \mathrm{~F} 1$ offspring on PND 56 to induce immunization. Blood was collected prior to immunization and on day 5 after immunization to observe the immunosuppressive response. Serum was separated from collected blood, and then anti-KLH IgM was analyzed using enzyme-linked immunosorbent assay kits (Abnova, Taiwan) according to the manufacturer's instruction. At scheduled termination (PND 61), all cohort 3 F1 offspring were euthanized with carbon dioxide, and then macroscopic observation was performed.

\subsubsection{Developmental respiratory toxicity (cohort 4)}

In-life observation, including mortality, general clinical signs, detailed clinical signs, body weight, food consumption, pulmonary function examinations, and micro-CT scan of the lungs were performed during the study. Mortality and general clinical signs were observed twice daily, and detailed clinical signs, body weight, and food consumption were monitored once weekly. Pulmonary function examinations and micro-CT scan of the lungs were performed before sacrificing the animals (at approximately 10 weeks of age). Pulmonary function examinations, including tidal volume, inspiratory time, expiratory time, respiratory frequency, minute ventilation, and enhanced pause were measured with a Nebulizer Control and Air Supply Model CAD 212 (EMMS, England) for five animals/sex/group in cohort 4. In addition, micro-CT scan of the lungs was performed with micro-CT NFR POLARIS-G90 (NanoFocusRay, Republic of Korea) under isoflurane anesthesia for the other five animals/sex/group in cohort 4.

Terminal observations, including macroscopic observation, lung weight determination, and microscopic observation were performed for all cohort 4 F1 offspring. At scheduled termination (at approximately 10 weeks of age), all cohort 1B F1 offspring were euthanized with carbon dioxide. Macroscopic observation was performed, and then lung weight was measured. Microscopic observation was performed for lung, trachea, nasal cavity, and larynx. Microscopic observation of vehicle control and high concentration groups and of any organs with macroscopic abnormalities were performed.

\subsection{Statistical Analysis}

Statistical analyses of all parameters were conducted with Statistical Analysis Systems (SAS Institute, USA) or Pristima System (Xybion, USA) based on the methods of other toxicology studies and our previous studies [32]. The data are represented as mean \pm standard deviation (SD) and were considered of statistical significance when $p<0.05$ or $p<0.01$. The litter was used as a statistical unit for analysis of litter data. Offspring body weight was analyzed using one-way analysis of covariance (ANCOVA), and the litter size was used as the covariate.

\section{Results}




\subsection{PHMG-P Exposure Analysis}

The atmospheric exposure conditions and actual PHMG-P concentrations in the whole-body chambers are shown in Table 1. Temperature, relative humidity, and exposure concentrations of each group met the criteria of this type of study. The average generated particle size for each PHMG-P-exposed group was $<1.0 \mu \mathrm{m}$ as analyzed by mass median aerodynamic diameter (MMAD) calculations. MMADs were within the guideline-recommended range of $\leq$ $2.0 \mu \mathrm{m}$. The generated PHMG-P particles were considered to be capable of being deposited in the lower respiratory tract. In all groups, atmosphere exposure conditions of the inhalation chambers were appropriate as specified by the OECD test guidelines [24]. The average actual concentrations of PHMG-P were $0.13,1.50$, and $3.29 \mathrm{mg} / \mathrm{m}^{3}$, which corresponded to $92.9 \%, 93.8 \%$, and $102.8 \%$ of the target concentration of the low, medium, and high concentrations, respectively.

Table 1

Exposure analysis of polyhexamethylene guanidine phosphate (PHMG-P) in whole-body inhalation chamber.

\begin{tabular}{|c|c|c|c|c|}
\hline & VC & T1 & T2 & T3 \\
\hline Target concentration $\left(\mathrm{mg} / \mathrm{m}^{3}\right)$ & 0 & 0.14 & 1.60 & 3.20 \\
\hline \multicolumn{5}{|l|}{ Exposure atmospheric condition } \\
\hline Temperature $\left({ }^{\circ} \mathrm{C}\right)$ & $\begin{array}{l}22.6 \pm \\
0.5^{a)}\end{array}$ & $22.9 \pm 0.5$ & $23.2 \pm 0.5$ & $22.9 \pm 0.5$ \\
\hline Relative humidity (\%) & $45.7 \pm 0.8$ & $49.0 \pm 0.7$ & $45.3 \pm 0.9$ & $47.7 \pm 0.6$ \\
\hline Actual average concentration $\left(\mathrm{mg} / \mathrm{m}^{3}\right)$ & ND & $\begin{array}{l}0.13 \pm \\
0.01\end{array}$ & $\begin{array}{l}1.50 \pm \\
0.06\end{array}$ & $\begin{array}{l}3.29 \pm \\
0.20\end{array}$ \\
\hline Actual/target ratio (\%) & ND & 92.9 & 93.8 & 102.8 \\
\hline \multicolumn{5}{|l|}{ Particle size } \\
\hline Mass median aerodynamic diameter(MMAD, $\mu \mathrm{m})$ & ND & $\begin{array}{l}0.28 \pm \\
0.04\end{array}$ & $\begin{array}{l}0.27 \pm \\
0.01\end{array}$ & $\begin{array}{l}0.45 \pm \\
0.03\end{array}$ \\
\hline Geometric standard deviation (GSD) & ND & $\begin{array}{l}3.92 \pm \\
1.75\end{array}$ & $\begin{array}{l}2.93 \pm \\
0.73\end{array}$ & $\begin{array}{l}1.84 \pm \\
0.14\end{array}$ \\
\hline \multicolumn{5}{|l|}{ ND: Not determined } \\
\hline
\end{tabular}

\subsection{Effects on PHMG-P-Exposed FO Females}

\subsubsection{Mortality and clinical observations}

Animal status and clinical signs of PHMG-P-exposed F0 females are presented in Table 2. Four females found dead were observed at $3.20 \mathrm{mg} / \mathrm{m}^{3}$ PHMG-P during the late period of pregnancy (GD 20-22). Abnormal pulmonary clinical signs were observed in these females, including increased respiration rate, irregular and/or noisy respiration, decreased body weight, and decreased food consumption. In addition, pale discoloration of lungs was observed in the necropsy. Nine dams without viable offspring were also observed at $3.20 \mathrm{mg} / \mathrm{m}^{3}$ 
PHMG-P on parturition day and the next day. Dams without viable offspring showed abnormalities similar to those observed in the dead females. Abnormal pulmonary clinical signs such as increased respiration rate, irregular and noisy respiration with thin appearance, and eye discharge were observed at $3.20 \mathrm{mg} / \mathrm{m}^{3} \mathrm{PHMG}-\mathrm{P}$.

Table 2

Animal status and clinical signs of polyhexamethylene guanidine phosphate (PHMG-P)-exposed F0 female rats.

\begin{tabular}{|c|c|c|c|c|}
\hline & \multicolumn{4}{|c|}{ PHMG-P $\left(\mathrm{mg} / \mathrm{m}^{3}\right)$} \\
\hline & 0 & 0.14 & 1.60 & 3.20 \\
\hline \multicolumn{5}{|l|}{ Animal status } \\
\hline Mating-proven females $(\mathrm{N})$ & 22 & 22 & 24 & 24 \\
\hline $\begin{array}{l}\text { Scheduled sacrificed } \\
\text { animals }(\mathbb{N})\end{array}$ & 22 & 21 & 23 & 10 \\
\hline \multicolumn{5}{|l|}{$\begin{array}{l}\text { Unscheduled sacrificed } \\
\text { animals }(\mathrm{N})\end{array}$} \\
\hline $\begin{array}{l}\text { Non-parturition (non- } \\
\text { pregnant) females }\end{array}$ & 0 & 1 & 1 & 1 \\
\hline Found dead & 0 & 0 & 0 & 4 \\
\hline Moribund & 0 & 0 & 0 & 0 \\
\hline $\begin{array}{l}\text { Dams without viable } \\
\text { offspring }\end{array}$ & 0 & 0 & 0 & 9 \\
\hline \multicolumn{5}{|l|}{ Clinical signs $(\mathrm{N})$} \\
\hline Increased respiration rate & 0 & 0 & 0 & 9 \\
\hline Irregular respiration & 0 & 0 & 0 & 21 \\
\hline Noisy respiration & 0 & 0 & 0 & 10 \\
\hline Eye discharge & 0 & 0 & 0 & 1 \\
\hline Thin appearance & 0 & 0 & 0 & 1 \\
\hline
\end{tabular}

\subsubsection{Body weight and food consumption}

Body weight of PHMG-P-exposed FO females during gestation and parturition day as well as of non-exposed surrogate mothers during lactation are presented in Fig. 2. Body weight of PHMG-P-exposed F0 females on GD 12-20 was lower (up to $72 \%$ of control) at $3.20 \mathrm{mg} / \mathrm{m}^{3} \mathrm{PHMG}-\mathrm{P}$. In addition, decreased body weight gain during pregnancy (GD 6-20,4\% of control) was also observed at $3.20 \mathrm{mg} / \mathrm{m}^{3}$ PHMG-P. At $1.60 \mathrm{mg} / \mathrm{m}^{3}$ PHMG-P, body weight gain of PHMG-P-exposed F0 females decreased during pregnancy (88\% of control). There were no significant changes in body weight of non-exposed surrogate mothers during lactation. 
Food consumption of PHMG-P-exposed F0 females during gestation and of non-exposed surrogate mothers during lactation is presented in Table 3. Food consumption of PHMG-P-exposed F0 females on GD 9-20 was lower (up to $18 \%$ of control) at $3.20 \mathrm{mg} / \mathrm{m}^{3}$ PHMG-P. In addition, decreased food consumption of PHMG-Pexposed F0 females on GD 18-20 (85\% of control) was also observed at $1.60 \mathrm{mg} / \mathrm{m}^{3} \mathrm{PHMG}$-P. Although decreased food consumption of non-exposed surrogate mothers was observed during lactation, it was not considered to be treatment-related because milk production was reduced owing to decreased offspring number and growth retardation in PHMG-P-exposed females. 
Table 3

Food consumption of polyhexamethylene guanidine phosphate (PHMG-P)-exposed F0 female rats during pregnancy and non-exposed surrogate mothers during lactation.

\begin{tabular}{|c|c|c|c|c|}
\hline & \multicolumn{4}{|c|}{ PHMG-P $\left(\mathrm{mg} / \mathrm{m}^{3}\right)$} \\
\hline & 0 & 0.14 & 1.60 & 3.20 \\
\hline $\begin{array}{l}\text { Pregnant PHMG-P-exposed F0 females during } \\
\text { pregnancy }(\mathrm{N})\end{array}$ & 22 & 21 & 23 & 23 \\
\hline \multicolumn{5}{|l|}{ Food consumption (g/animal/day) } \\
\hline Gestation day 6-9 & $\begin{array}{l}25.2 \pm \\
2.5^{a)}\end{array}$ & $\begin{array}{l}25.9 \pm \\
2.1\end{array}$ & $25.6 \pm 1.7$ & $24.1 \pm 2.2$ \\
\hline Gestation day $9-12$ & $27.2 \pm 2.1$ & $\begin{array}{l}28.5 \pm \\
2.6\end{array}$ & $27.8 \pm 2.0$ & $23.5 \pm 2.5^{\star \star}$ \\
\hline Gestation day $12-15$ & $28.1 \pm 2.6$ & $\begin{array}{l}28.3 \pm \\
2.2\end{array}$ & $27.2 \pm 2.0$ & $18.4 \pm 4.6^{\star \star}$ \\
\hline Gestation day $15-18$ & $27.8 \pm 2.5$ & $\begin{array}{l}29.5 \pm \\
2.1\end{array}$ & $26.9 \pm 2.2$ & $12.6 \pm 4.5^{\star \star}$ \\
\hline Gestation day $18-20$ & $27.2 \pm 2.8$ & $\begin{array}{l}28.1 \pm \\
1.9\end{array}$ & $\begin{array}{l}23.1 \pm \\
3.1 * \star\end{array}$ & $4.8 \pm 4.7^{\star \star}$ \\
\hline \multicolumn{5}{|l|}{ Food consumption interval (g/animal/day) } \\
\hline Gestation day 6-20 & $27.1 \pm 2.2$ & $\begin{array}{l}28.1 \pm \\
1.9\end{array}$ & $26.3 \pm 1.7$ & $17.5 \pm 2.4^{\star *}$ \\
\hline Non-exposed surrogate mothers during lactation $(\mathrm{N})$ & 22 & 21 & 23 & 10 \\
\hline \multicolumn{5}{|l|}{ Food consumption (g/animal/day) } \\
\hline Lactation day $0-4$ & $41.6 \pm 5.3$ & $\begin{array}{l}41.2 \pm \\
5.6\end{array}$ & $40.2 \pm 5.2$ & $33.7 \pm 5.4^{\star \star}$ \\
\hline Lactation day 4-7 & $54.7 \pm 4.6$ & $\begin{array}{l}54.7 \pm \\
3.4\end{array}$ & $53.1 \pm 7.2$ & $45.8 \pm 8.2^{\star}$ \\
\hline Lactation day 7-14 & $66.9 \pm 4.5$ & $\begin{array}{l}64.8 \pm \\
4.1\end{array}$ & $62.8 \pm 7.5$ & $57.9 \pm 7.9 * *$ \\
\hline Lactation day $14-21$ & $77.2 \pm 6.5$ & $\begin{array}{l}75.8 \pm \\
4.2\end{array}$ & $73.9 \pm 7.8$ & $\begin{array}{l}66.6 \pm \\
11.0^{\star \star}\end{array}$ \\
\hline \multicolumn{5}{|l|}{ Food consumption interval (g/animal/day) } \\
\hline Lactation day $0-21$ & $63.8 \pm 4.5$ & $\begin{array}{l}62.5 \pm \\
3.3\end{array}$ & $60.8 \pm 6.5$ & $54.5 \pm 8.2^{* *}$ \\
\hline \multicolumn{5}{|l|}{ a) Values are means \pm standard deviation. } \\
\hline control group & & & & \\
\hline
\end{tabular}

\subsubsection{Parturition monitoring}


Parturition monitoring of PHMG-P-exposed FO females is presented in Table 4. Gestation period was increased (22.2 vs. 21.6 in the negative control) at $3.20 \mathrm{mg} / \mathrm{m}^{3}$ PHMG-P. Perinatal death rates increased (2.1 vs. $0.1 \mathrm{in}$ the negative control) at $3.20 \mathrm{mg} / \mathrm{m}^{3}$ PHMG-P, and it was correlated with increased unaccounted-for sites (\% of postimplantation death, 3.14-fold over control) and decreased number of offspring born ( $90 \%$ of control) during parturition.

Table 4

Parturition monitoring of polyhexamethylene guanidine phosphate (PHMG-P)-exposed F0 female rats.

\begin{tabular}{|c|c|c|c|c|}
\hline & \multicolumn{4}{|c|}{ PHMG-P $\left(\mathrm{mg} / \mathrm{m}^{3}\right)$} \\
\hline & 0 & 0.14 & 1.60 & 3.20 \\
\hline $\begin{array}{l}\text { Pregnant PHMG-P-exposed F0 females at parturition } \\
(\mathrm{N})\end{array}$ & 22 & 21 & 23 & 19 \\
\hline Gestation period (days) & $\begin{array}{l}21.6 \pm \\
0.3^{a)}\end{array}$ & $21.6 \pm 0.3$ & $21.7 \pm 0.4$ & $22.2 \pm 0.6^{\star \star *}$ \\
\hline Implantations (N) & $15.0 \pm 1.9$ & $15.0 \pm 1.5$ & $15.4 \pm 1.5$ & $14.8 \pm 2.3$ \\
\hline Offspring born $(\mathrm{N})$ & $14.3 \pm 1.9$ & $14.0 \pm 1.9$ & $14.7 \pm 1.6$ & $12.8 \pm 3.1$ \\
\hline Perinatal death $(\mathrm{N})$ & $0.1 \pm 0.4$ & $0.0 \pm 0.0$ & $0.2 \pm 0.4$ & $2.1 \pm 3.5^{\star \star}$ \\
\hline Unaccounted-for sites $\left.{ }^{\mathrm{b}}\right)(\%)$ & $4.4 \pm 6.0$ & $6.1 \pm 8.4$ & $4.5 \pm 4.6$ & $\begin{array}{l}13.8 \pm \\
15.4^{\star \star}\end{array}$ \\
\hline Sex ratioc) $(\%)$ & $\begin{array}{l}50.9 \pm \\
12.2\end{array}$ & $\begin{array}{l}51.2 \pm \\
16.2\end{array}$ & $\begin{array}{l}52.7 \pm \\
11.4\end{array}$ & $51.0 \pm 11.6$ \\
\hline Offspring with external abnormalities (N) & 0 & 0 & 0 & 0 \\
\hline Delivery index $\left.{ }^{\mathrm{d}}\right)(\%)$ & 100.0 & 100.0 & 100.0 & 94.7 \\
\hline \multicolumn{5}{|l|}{ a) Values are means \pm standard deviation. } \\
\hline \multicolumn{5}{|c|}{ b) (No. of implantation sites/litter) - (No. of live offspring at birth/litter) / No. of implantation sites/litter $\times 100$} \\
\hline \multicolumn{5}{|c|}{ c) (No. of male offspring on PND 0/litter) / (No. of total offspring on PND 0/litter) $\times 100$} \\
\hline \multicolumn{5}{|c|}{ d) No. of dams with live offspring / No. of pregnant dams $\times 100$} \\
\hline
\end{tabular}

\subsubsection{Macroscopic observation}

Macroscopic observation of PHMG-P-exposed F0 females is presented in Table 5. Discoloration of lungs, small thymus, and small spleen were observed at $3.20 \mathrm{mg} / \mathrm{m}^{3}$ PHMG-P. In addition, discoloration of lungs was also observed at $1.60 \mathrm{mg} / \mathrm{m}^{3}$ PHMG-P. 
Table 5

Macroscopic observation of polyhexamethylene guanidine phosphate

(PHMG-P)-exposed F0 female rats.

\begin{tabular}{|lllll|}
\hline & PHMG-P $\left(\mathrm{mg} / \mathrm{m}^{3}\right)$ & \\
\hline Pregnant PHMG-P-exposed F0 females (N) & 22 & 21 & 23 & 23 \\
\hline Lungs, discoloration & 1 & 0 & 11 & 19 \\
\hline Thymus, small & 0 & 0 & 0 & 14 \\
\hline Spleen, small & 0 & 0 & 0 & 1 \\
\hline
\end{tabular}

\subsection{Effects on Prenatally PHMG-P-exposed F1 Offspring during Lactation}

Live litter size and body weight of prenatally PHMG-P-exposed F1 offspring during lactation are presented in Table 6. Decreased live litter size during lactation (up to $72 \%$ of control) and decreased viability index (\% of survival rate from birth to PND 4,77\% of control) were observed at $3.20 \mathrm{mg} / \mathrm{m}^{3} \mathrm{PHMG}-\mathrm{P}$. In addition, slightly decreased viability index ( $94 \%$ of control) at $1.60 \mathrm{mg} / \mathrm{m}^{3}$ PHMG-P was also observed. Both male and female offspring body weight during lactation was lower from birth to weaning (up to $66 \%$ of control) at $3.20 \mathrm{mg} / \mathrm{m}^{3}$ PHMG-P. Swollen of abdomen was observed during lactation in two offspring at $3.20 \mathrm{mg} / \mathrm{m}^{3}$ PHMG-P (data not shown). In contrast, no PHMG-P-related change was observed in anogenital distance, nipple retention, macroscopic observation, organ weight, or thyroid hormone analysis of F1 offspring during lactation (data not shown). 
Table 6

Live litter size and body weight of prenatally polyhexamethylene guanidine phosphate (PHMG-P)-exposed F1 offspring during lactation.

\begin{tabular}{|c|c|c|c|c|}
\hline & \multicolumn{4}{|c|}{ PHMG-P (mg/m³) } \\
\hline & 0 & 0.14 & 1.60 & 3.20 \\
\hline $\begin{array}{l}\text { Pregnant PHMG-P-exposed FO females at parturition } \\
(\mathrm{N})\end{array}$ & 22 & 21 & 23 & 19 \\
\hline \multicolumn{5}{|l|}{ Live litter size $(\mathrm{N})$} \\
\hline PND 0 & $\begin{array}{l}14.2 \pm \\
1.8^{a)}\end{array}$ & $14.0 \pm 1.9$ & $14.5 \pm 1.6$ & $10.7 \pm 4.8^{\star \star}$ \\
\hline PND 4 & $14.0 \pm 1.9$ & $13.7 \pm 2.1$ & $13.6 \pm 2.3$ & $10.1 \pm 3.8 * \star$ \\
\hline PND 4 (after culling) & $10.0 \pm 0.0$ & $10.0 \pm 0.0$ & $9.8 \pm 0.6$ & $9.1 \pm 2.9 * *$ \\
\hline PND 21 & $10.0 \pm 0.0$ & $10.0 \pm 0.0$ & $9.6 \pm 1.3$ & $9.1 \pm 2.9 \star \star$ \\
\hline \multicolumn{5}{|l|}{ Live litter size-related index (\%) } \\
\hline Viability index $\left.{ }^{b}\right)(\%)$ & $99.0 \pm 2.7$ & $97.6 \pm 6.6$ & $\begin{array}{l}93.8 \pm \\
12.6\end{array}$ & $\begin{array}{l}75.8 \pm \\
25.3^{\star \star}\end{array}$ \\
\hline Weaning index ${ }^{c}(\%)$ & $\begin{array}{l}100.0 \pm \\
0.0\end{array}$ & $\begin{array}{l}100.0 \pm \\
0.0\end{array}$ & $\begin{array}{l}97.4 \pm \\
10.5\end{array}$ & $100.0 \pm 0.0$ \\
\hline \multicolumn{5}{|l|}{ F1 offspring body weight (g) } \\
\hline \multicolumn{5}{|l|}{ Male offspring } \\
\hline PND 0 & $6.6 \pm 0.5$ & $6.6 \pm 0.5$ & $6.2 \pm 0.6$ & $4.4 \pm 0.8^{\star \star}$ \\
\hline Covariate adjusted mean & 6.6 & 6.7 & 6.3 & $4.3^{\star \star}$ \\
\hline PND 4 (pre-cull) & $10.9 \pm 1.1$ & $10.9 \pm 1.2$ & $10.5 \pm 1.4$ & $8.9 \pm 1.8 * \star$ \\
\hline Covariate adjusted mean & 11.0 & 10.9 & 10.5 & $8.7^{\star \star}$ \\
\hline PND 4 (post-cull) & $11.0 \pm 1.0$ & $11.0 \pm 1.2$ & $10.6 \pm 1.4$ & $9.0 \pm 1.9 * \star$ \\
\hline PND 7 & $17.6 \pm 1.3$ & $17.5 \pm 1.7$ & $17.0 \pm 2.5$ & $14.2 \pm 2.9 * \star$ \\
\hline PND 14 & $33.8 \pm 1.8$ & $33.0 \pm 2.5$ & $32.6 \pm 3.3$ & $28.9 \pm 4.5^{\star \star}$ \\
\hline PND 21 & $55.9 \pm 4.7$ & $54.3 \pm 4.9$ & $54.1 \pm 5.4$ & $48.2 \pm 7.1^{\star \star}$ \\
\hline \multicolumn{5}{|l|}{ Female offspring } \\
\hline PND 0 & $6.2 \pm 0.4$ & $6.2 \pm 0.5$ & $5.9 \pm 0.6$ & $4.1 \pm 0.8 * \star$ \\
\hline \multicolumn{5}{|l|}{ a) Values are means \pm standard deviation. } \\
\hline \multicolumn{5}{|c|}{ b) (No. of live off spring on PND 4/litter) / (No. of live offspring at birth/litter) × 100} \\
\hline \multicolumn{5}{|c|}{ c) (No. of live offspring on PND 21/litter) / (No. of live offspring on PND 4 after culling/litter) × 100} \\
\hline${ }^{\star *} p<0.01$, compared with control group & & & & \\
\hline
\end{tabular}




\begin{tabular}{|c|c|c|c|c|}
\hline \multirow[b]{2}{*}{ Covariate adjusted mean } & \multicolumn{4}{|c|}{ PHMG-P $\left(\mathrm{mg} / \mathrm{m}^{3}\right)$} \\
\hline & 6.2 & 6.2 & 5.9 & $4.1^{\star \star}$ \\
\hline PND 4 (pre-cull) & $10.4 \pm 1.1$ & $10.3 \pm 1.2$ & $10.1 \pm 1.6$ & $8.1 \pm 1.7^{\star \star}$ \\
\hline Covariate adjusted mean & 10.5 & 10.3 & 10.1 & $7.9 * \star$ \\
\hline PND 4 (post-cull) & $10.6 \pm 1.2$ & $10.5 \pm 1.1$ & $10.2 \pm 1.6$ & $8.2 \pm 1.7^{\star \star}$ \\
\hline PND 7 & $16.9 \pm 1.6$ & $16.7 \pm 1.6$ & $16.8 \pm 1.4$ & $13.0 \pm 2.9 * \star$ \\
\hline PND 14 & $32.7 \pm 2.4$ & $31.8 \pm 2.3$ & $32.2 \pm 2.1$ & $27.8 \pm 3.9 \star \star$ \\
\hline PND 21 & $54.2 \pm 5.4$ & $52.7 \pm 4.3$ & $53.6 \pm 3.3$ & $46.5 \pm 5.6^{\star \star}$ \\
\hline \multicolumn{5}{|c|}{ a) Values are means \pm standard deviation. } \\
\hline \multicolumn{5}{|c|}{ b) (No. of live offspring on PND 4/litter) / (No. of live offspring at birth/litter) $\times 100$} \\
\hline \multicolumn{5}{|c|}{ c) (No. of live offspring on PND 21/litter) / (No. of live offspring on PND 4 after culling/litter) × 100} \\
\hline \multicolumn{5}{|c|}{$\star \star p<0.01$, compared with control group } \\
\hline
\end{tabular}

A summary of the results for prenatally PHMG-P-exposed F1 offspring after weaning is presented in Table 7. 
Table 7

Summary of study results for prenatally polyhexamethylene guanidine phosphate (PHMG-P)-exposed F1 offspring after weaning.

\begin{tabular}{|c|c|c|}
\hline Cohort (included group) & PHMG-P-related changes (Group) & No change \\
\hline $\begin{array}{l}1 \mathrm{~A} ; \text { General systemic } \\
\text { toxicity } \\
(\mathrm{VC}, \mathrm{T} 1, \mathrm{~T} 2 \text {, and } \mathrm{T} 3)\end{array}$ & $\begin{array}{l}\text { - Body weight } \downarrow \text { (T3; males and females) } \\
\text { - Food consumption } \downarrow \text { (T3; males and } \\
\text { females) }\end{array}$ & $\begin{array}{l}\text { - Mortality } \\
\text { - General and detailed clinical } \\
\text { signs } \\
\text { - Sexual maturity } \\
\text { - First estrus examination } \\
\text { - Estrus cycle } \\
\text { - Macroscopic observation } \\
\text { - Clinical pathology } \\
\text { - Organ weights } \\
\text { - Microscopic observation } \\
\text { - Sperm analysis } \\
\text { - Lymphoid analysis } \\
\text { - Thyroid hormone analysis }\end{array}$ \\
\hline $\begin{array}{l}\text { 1B; Reproductive toxicity } \\
\text { (VC, T1, and T2) }\end{array}$ & No PHMG-P-related changes & $\begin{array}{l}\text { - Mortality } \\
\text { - General and detailed clinical } \\
\text { signs } \\
\text { - Body weight } \\
\text { - Food consumption } \\
\text { - Sexual maturity } \\
\text { - Precoital time } \\
\text { - Fertility indices } \\
\text { - Parturition monitoring } \\
\text { - F2 offspring observations } \\
\text { - Macroscopic observation } \\
\text { - Organ weights } \\
\text { - Thyroid hormone analysis }\end{array}$ \\
\hline
\end{tabular}




\begin{tabular}{|c|c|c|}
\hline Cohort (included group) & PHMG-P-related changes (Group) & No change \\
\hline $\begin{array}{l}\text { 2A; Developmental } \\
\text { neurotoxicity for adult } \\
(\mathrm{VC}, \mathrm{T} 1, \mathrm{~T} 2 \text {, and } \mathrm{T} 3)\end{array}$ & $\begin{array}{l}\text { - General and detailed clinical signs; } \\
\text { abdominal swollen (T3; male) } \\
\text { - Body weight } \downarrow \text { (T3; males and females) } \\
\text { - Food consumption } \downarrow \text { (T3; males and } \\
\text { females) }\end{array}$ & $\begin{array}{l}\text { - Mortality } \\
\text { - Sexual maturity } \\
\text { - Auditory startle response } \\
\text { - Functional observation } \\
\text { battery } \\
\text { - Motor activity } \\
\text { - Macroscopic observation } \\
\text { - Brain weight } \\
\text { - Neurohistopathology }\end{array}$ \\
\hline $\begin{array}{l}\text { 2B; Developmental } \\
\text { neurotoxicity for young } \\
(\mathrm{VC}, \mathrm{T} 1 \text {, and T2) }\end{array}$ & No PHMG-P-related changes & $\begin{array}{l}\text { - Mortality } \\
\text { - Macroscopic observation } \\
\text { - Brain weight } \\
\text { - Neurohistopathology }\end{array}$ \\
\hline $\begin{array}{l}\text { 3; Developmental } \\
\text { immunotoxicity } \\
(\mathrm{VC}, \mathrm{T} 1, \mathrm{~T} 2 \text {, and } \mathrm{T} 3)\end{array}$ & $\begin{array}{l}\text { - Body weight } \downarrow \text { (T3; males and females) } \\
\text { - Food consumption } \downarrow \text { (T3; males and } \\
\text { females) }\end{array}$ & $\begin{array}{l}\text { - Mortality } \\
\text { - General and detailed clinical } \\
\text { signs } \\
\text { - Sexual maturity } \\
\text { - Macroscopic observation } \\
\text { - Immunosuppressive response }\end{array}$ \\
\hline $\begin{array}{l}\text { 4; Developmental } \\
\text { respiratory toxicity } \\
(\mathrm{VC}, \mathrm{T} 1, \mathrm{~T} 2 \text {, and } \mathrm{T} 3)\end{array}$ & $\begin{array}{l}\text { - Body weight } \downarrow \text { (T3; males and females) } \\
\text { - Food consumption } \downarrow \text { (T3; females) }\end{array}$ & $\begin{array}{l}\text { - Mortality } \\
\text { - General and detailed clinical } \\
\text { signs } \\
\text { - Sexual maturity } \\
\text { - Micro-CT examination of } \\
\text { lungs } \\
\text { - Respiratory functions } \\
\text { - Macroscopic observation } \\
\text { - Lungs weight } \\
\text { - Microscopic observation for } \\
\text { respiratory organs }\end{array}$ \\
\hline
\end{tabular}

3.4.1. General systemic toxicity (cohort 1A) 
Body weight and food consumption of prenatally PHMG-P-exposed F1 offspring in cohort $1 \mathrm{~A}$ are presented in Fig. 3 and Table 8. Body weight of prenatally PHMG-P-exposed F1 offspring was lower (up to 85\% of control) at $3.20 \mathrm{mg} / \mathrm{m}^{3}$ PHMG-P. In addition, a correlated food consumption decrease in prenatally PHMG-P-exposed F1 offspring (up to $90 \%$ of control) was observed during the few weeks after weaning at $3.20 \mathrm{mg} / \mathrm{m}^{3} \mathrm{PHMG}-\mathrm{P}$. No significant changes were observed in mortality, general and detailed clinical signs, sexual maturity, first estrus examination, estrus cycle, macroscopic observation, clinical pathology, organ weight, microscopic observation, sperm analysis, lymphoid analysis, or thyroid hormone analysis. 
Table 8

Food consumption of prenatally polyhexamethylene guanidine phosphate (PHMG-P)-exposed F1 offspring in cohort $1 \mathrm{~A}$ after weaning.

\begin{tabular}{|c|c|c|c|c|}
\hline & \multicolumn{4}{|c|}{ PHMG-P $\left(\mathrm{mg} / \mathrm{m}^{3}\right)$} \\
\hline & 0 & 0.14 & 1.60 & 3.20 \\
\hline Males (N) & 20 & 20 & 20 & 17 \\
\hline \multicolumn{5}{|l|}{ Food consumption (g/animal/day) } \\
\hline Post-natal day $21-28$ & $14.0 \pm 0.6^{a)}$ & $13.6 \pm 0.8$ & $13.5 \pm 0.7$ & $12.7 \pm 1.0$ ** \\
\hline Post-natal day 28-35 & $20.7 \pm 1.0$ & $20.5 \pm 1.3$ & $20.4 \pm 0.9$ & $19.0 \pm 1.6$ ** \\
\hline Post-natal day $35-42$ & $27.3 \pm 1.3$ & $27.1 \pm 1.9$ & $27.2 \pm 1.8$ & $25.4 \pm 2.0$ ** \\
\hline Post-natal day $42-49$ & $32.2 \pm 1.9$ & $32.7 \pm 2.2$ & $32.1 \pm 2.3$ & $30.4 \pm 2.1^{\star}$ \\
\hline Post-natal day 49-56 & $35.5 \pm 2.2$ & $35.8 \pm 2.3$ & $36.1 \pm 3.2$ & $34.3 \pm 2.3$ \\
\hline Post-natal day 56-63 & $35.5 \pm 2.2$ & $36.4 \pm 2.7$ & $35.8 \pm 3.4$ & $34.7 \pm 2.2$ \\
\hline Post-natal day $63-70$ & $35.9 \pm 2.7$ & $36.5 \pm 2.5$ & $36.3 \pm 2.7$ & $35.0 \pm 2.0$ \\
\hline Post-natal day $70-77$ & $35.6 \pm 2.5$ & $36.7 \pm 2.5$ & $36.4 \pm 2.8$ & $35.4 \pm 2.2$ \\
\hline Post-natal day 77-84 & $35.9 \pm 2.1$ & $37.0 \pm 2.9$ & $36.7 \pm 2.8$ & $34.7 \pm 1.5$ \\
\hline Post-natal day 84-90 & $36.3 \pm 2.1$ & $36.7 \pm 3.0$ & $36.2 \pm 2.9$ & $34.3 \pm 1.8$ \\
\hline Interval data (Post-natal day $21-90)$ & $31.0 \pm 1.5$ & $29.6 \pm 2.1$ & $30.2 \pm 2.3$ & $30.4 \pm 2.4$ \\
\hline Females (N) & 20 & 20 & 20 & 14 \\
\hline \multicolumn{5}{|l|}{ Food consumption (g/animal/day) } \\
\hline Post-natal day 21-28 & $13.4 \pm 0.9$ & $13.1 \pm 0.7$ & $13.2 \pm 0.7$ & $12.1 \pm 0.6^{\star \star}$ \\
\hline Post-natal day 28-35 & $18.3 \pm 1.0$ & $18.0 \pm 0.9$ & $18.5 \pm 1.2$ & $17.2 \pm 1.0$ ** \\
\hline Post-natal day 35-42 & $21.3 \pm 1.6$ & $21.7 \pm 1.1$ & $21.8 \pm 1.5$ & $20.7 \pm 1.0$ \\
\hline Post-natal day 42-49 & $23.7 \pm 1.2$ & $23.4 \pm 1.1$ & $23.7 \pm 1.5$ & $22.6 \pm 1.3$ \\
\hline Post-natal day 49-56 & $26.5 \pm 3.4$ & $25.7 \pm 1.6$ & $25.0 \pm 1.7$ & $24.5 \pm 1.6$ \\
\hline Post-natal day 56-63 & $24.7 \pm 1.6$ & $25.1 \pm 1.7$ & $24.5 \pm 1.4$ & $24.3 \pm 1.6$ \\
\hline Post-natal day 63-70 & $25.9 \pm 1.9$ & $25.4 \pm 2.0$ & $25.5 \pm 1.3$ & $25.6 \pm 1.5$ \\
\hline Post-natal day 70-77 & $25.0 \pm 1.1$ & $25.4 \pm 2.2$ & $24.3 \pm 1.7$ & $25.4 \pm 1.6$ \\
\hline Post-natal day 77-84 & $25.3 \pm 1.8$ & $26.3 \pm 2.2$ & $25.1 \pm 2.7$ & $25.2 \pm 1.4$ \\
\hline Post-natal day 84-90 & $24.7 \pm 1.5$ & $25.4 \pm 1.9$ & $25.6 \pm 2.6$ & $24.1 \pm 1.9$ \\
\hline
\end{tabular}

a) Values are means \pm standard deviation.

${ }^{*} p<0.05$ and ${ }^{* *} p<0.01$, compared with control group 


\begin{tabular}{|c|c|c|c|c|}
\hline \multicolumn{5}{|c|}{ PHMG-P $\left(\mathrm{mg} / \mathrm{m}^{3}\right)$} \\
\hline Interval data (Post-natal day 21-90) & $22.1 \pm 1.2$ & $21.6 \pm 2.3$ & $21.4 \pm 1.0$ & $21.2 \pm 0.8$ \\
\hline \multicolumn{5}{|c|}{ a) Values are means \pm standard deviation. } \\
\hline \multicolumn{5}{|c|}{${ }^{*} p<0.05$ and ${ }^{*} p<0.01$, compared with control group } \\
\hline
\end{tabular}

No significant changes were observed in mortality, general and detailed clinical signs, body weight, food consumption, sexual maturity, precoital time, fertility indices, parturition monitoring, F2 offspring observations, macroscopic observation, organ weight, or thyroid hormone analysis.

\subsubsection{Developmental neurotoxicity for adults (cohort 2A)}

Abdominal swollen was observed in one F1 male offspring at $3.20 \mathrm{mg} / \mathrm{m}^{3}$ PHMG-P. Body weight and food consumption of prenatally PHMG-P-exposed F1 offspring were lower (up to $82 \%$ of control) at $3.20 \mathrm{mg} / \mathrm{m}^{3}$ PHMG-P. No significant changes were observed in mortality, sexual maturity, auditory startle response, FOB, motor activity, macroscopic observation, brain weight, or neurohistopathology.

\subsubsection{Developmental neurotoxicity for young (cohort 2B)}

No significant changes were observed in mortality, macroscopic observation, brain weight, or neurohistopathology.

\subsubsection{Developmental immunotoxicity (cohort 3)}

Body weight and food consumption of prenatally PHMG-P-exposed F1 offspring were lower (up to $79 \%$ of control) at $3.20 \mathrm{mg} / \mathrm{m}^{3}$ PHMG-P (data not shown). No significant changes were observed in mortality, general and detailed clinical signs, sexual maturity, macroscopic observation, or immunosuppressive response.

\subsubsection{Developmental respiratory toxicity (cohort 4)}

Body weight of prenatally PHMG-P-exposed F1 offspring were lower (up to $86 \%$ of control) at $3.20 \mathrm{mg} / \mathrm{m}^{3} \mathrm{PHMG}$ $P$, and a correlated decrease in food consumption ( $87 \%$ of control) was also observed in females at $3.20 \mathrm{mg} / \mathrm{m}^{3}$ PHMG-P. No significant changes were observed in mortality, general and detailed clinical signs, sexual maturity, micro-CT examination of the lungs (Fig. 4), respiratory functions, macroscopic observation, lung weight, or microscopic observation of respiratory organs (Fig. 5).

\section{Discussion}

The objective of this study was to investigate the postnatal development of prenatally PHMG-P-exposed offspring with a modified extended one-generation reproductive toxicity study design following OECD test guidelines for the testing of chemicals [22]. Prenatally PHMG-P-exposed offspring showed general systemic toxicities at birth and thereafter, and PHMG-P-exposed pregnant rats also showed severe general systemic toxicities at an exposure level equivalent to that of humans. In addition, PHMG-P-related reproductive and developmental toxicities such as increased gestation period and increased perinatal death rates were also observed in pregnant rats and their offspring, respectively. 
PHMG-P inhalation exposure of pregnant rats during pregnancy induced pulmonary toxicities at $\geq 1.60 \mathrm{mg} / \mathrm{m}^{3}$ PHMG-P. Pulmonary toxicities induced increased respiration rate, irregular respiration, and noisy respiration. In addition, discoloration of lungs was also observed at $3.20 \mathrm{mg} / \mathrm{m}^{3}$ PHMG-P, which is considered to be equivalent to exposure levels to human [25]. The pulmonary system toxicities observed in pregnant rats in this study are consistent with our previous inhalation toxicity studies with rats as well as clinical investigations in humans [6, 7 , 21]. PHMG-P inhalation exposure also caused pulmonary and general systemic toxicities at $1.60 \mathrm{mg} / \mathrm{m}^{3}$, including decreased body weight gain during pregnancy, decreased food consumption during the late period of pregnancy, and discoloration of lungs. Previous studies have reported that increased expression of cytokines is the primary cause of PHMG-P-induced pulmonary toxicities [13, 14, 33]. Accordingly, these inflammatory responses are considered to result in chronic lung fibrosis and related pulmonary toxicity findings [34].

PHMG-P inhalation exposure during pregnancy also induced reproductive and developmental toxicities to pregnant rats and their offspring at $\geq 1.60 \mathrm{mg} / \mathrm{m}^{3} \mathrm{PHMG}-\mathrm{P}$, and increased gestation period was observed in pregnant rats at $3.20 \mathrm{mg} / \mathrm{m}^{3}$ PHMG-P. Gestation period change is considered to be related with fetal growth retardation and hormonal changes [35]. Decreased offspring body weigh at birth was also observed at $3.20 \mathrm{mg} / \mathrm{m}^{3}$ PHMG-P, and therefore increased gestation period in this study is considered to be linked with fetal growth retardation. Increased perinatal death rates near parturition and increased offspring death rates after parturition were also observed at $3.20 \mathrm{mg} / \mathrm{m}^{3}$ PHMG-P. In particular, dams with total offspring death were clearly observed at $3.20 \mathrm{mg} / \mathrm{m}^{3}$ PHMG-P. Total offspring death occurs infrequently, and viable litter size is a stable parameter in rats [35]. Reduced offspring survival can result from several factors, including maternal health, structural abnormalities, insufficient milk, and prenatal exposure [36]. In this study, reduced offspring survival during parturition and weaning was considered to be caused by severe maternal systemic toxicities during pregnancy, considering that no structural abnormalities or increased prenatal death rates were observed in a previous prenatal toxicity study [21]. In addition, we conducted a cross-fostering method to minimize the secondary maternal effects after parturition. Decreased viability index (postnatal survival of offspring between birth and PND 4) was also observed at $1.60 \mathrm{mg} / \mathrm{m}^{3}$ PHMG-P, and therefore we could confirm that maternal systemic toxicities during pregnancy also adversely affected the general health conditions of prenatally PHMG-Pexposed offspring.

Decreased body weight at birth in prenatally PHMG-P-exposed offspring was also observed at $3.20 \mathrm{mg} / \mathrm{m}^{3}$ PHMG-P. Offspring body weight at birth is generally influenced by maternal body weight as a reflection of nutritional status during pregnancy $[37,38]$. In this study, decreased maternal body weight during pregnancy was observed, and therefore decreased body weight of prenatally PHMG-P-exposed offspring was considered to be induced by growth retardation in utero. In addition, body weight was lower than the control during lactation and after weaning, with a correlated decreased in food consumption. Decreased body weight is considered to be one of the representative toxicity-based endpoints in general systemic functions in toxicity studies [39], and therefore decreased body weight of prenatally PHMG-P-exposed offspring at $3.20 \mathrm{mg} / \mathrm{m}^{3} \mathrm{PHMG}-\mathrm{P}$ was considered to be PHMG-P inhalation exposure-related toxicity. At $3.20 \mathrm{mg} / \mathrm{m}^{3}$ PHMG-P, a swollen of abdomen was also observed during lactation and after weaning. Although it was observed only in a small number of animals, it was considered to be a potential PHMG-P exposure-related toxicity because it is not a common finding in rats. In addition, general systemic toxicities were also observed at this PHMG-P exposure level. 
Maternal health during pregnancy is an important factor for offspring's future health [40,41]. Previous studies on the developmental origins of health and disease demonstrated that high levels of maternal stress perceived during pregnancy is related to developmental problems, including low birth weight, chronic immune diseases, and impaired metabolic function $[42,43,44]$. In particular, offspring born with low body weight have higher rates of asthma, poor vision, and poor academic performance [45]. Baker et al. [46] also reported that low body weight effects at parturition persist in adult life, with increased rates of cardiovascular disease and non-insulin dependent diabetes mellitus. Significant low body weight at birth and thereafter of prenatally PHMG-P-exposed offspring were also observed in this study, and therefore we suspect that prenatal PHMG-P exposure affects the future health of offspring. Although there were no significant PHMG-P-related changes in other examined parameters of prenatally PHMG-P-exposed offspring in this study, we cannot exclude that prenatal PHMG-P exposure induced abnormalities in other organs and systems. The current regulatory test guidelines use animal data to identify whether a hazard exists, but test guidelines also have limitations and are unable to help identify every hazard to humans [35].

In clinical investigations, pregnant women account for the majority of humidifier disinfectant-related fatal pulmonary disease, and are generally regarded as the most sensitive and susceptible group to these agents [13, 47]. Pregnant women are more easily exposed to humidifier disinfectants than other groups because they initiate use of humidifiers throughout the dry winter season in Korea to more carefully manage their health status during pregnancy [48]. In addition, pregnant women have higher levels of tidal volume and respiratory rates than nonpregnant women because of increased progesterone levels combined with uterine distention during pregnancy [49]. However, there are no reported human studies about offspring being prenatally exposed to PHMG-P in utero. Considering that an investigation of the potential health effects on prenatally PHMG-P-exposed humans from birth to maturity is very time consuming or impractical, our study results will be useful in human risk assessment.

Young children also account for many humidifier disinfectant-related fatal pulmonary diseases and are considered to be vulnerable to these agents $[50,51]$. Although we investigated the postnatal development of prenatally PHMG-P-exposed offspring with rats, we did not examine the potential toxicities of direct PHMG-P exposure of neonates, infants, or juveniles. Therefore, further toxicity studies of these vulnerable age groups are needed to comprehensively characterize the PHMG-P-induced toxicities in humans. However, our study results can also be partly extrapolated from these relatively short-lived experimental animals to long term health effects of PHMG-P exposure in humans.

In conclusion, this is the first study to investigate the postnatal development of prenatally PHMG-P-exposed offspring as well as examine the reproductive and developmental effects of females with PHMG-P inhalation exposure during pregnancy. We confirmed that increased gestation period, increased perinatal death rates, decreased offspring survival after birth, and decreased body weight at birth and thereafter were observed at $3.20 \mathrm{mg} / \mathrm{m}^{3}$ PHMG-P. In addition, prenatal PHMG-P exposure at $1.60 \mathrm{mg} / \mathrm{m}^{3}$ also resulted in decreased offspring survival after birth. These postnatal development toxicity findings were observed with systemic maternal toxicities during pregnancy. The results of this study could be used for risk assessment of postnatal development of prenatally PHMG-P-exposed offspring as well as reproductive and developmental effects on females with PHMG-P inhalation exposure during pregnancy. Further studies with direct PHMG-P exposure to young animals will be valuable to improve our understanding of the potential hazards to humans.

\section{Abbreviations}


AAALAC: Association for Assessment and Accreditation of Laboratory Animal Care International, ANCOVA: Analysis of covariance, ANOVA: Analysis of variance, CT: Computed tomography, EOGRTS: Extended onegeneration reproductive toxicity study, FOB: Functional observation battery, GD: Gestation day, GSD: Geometric standard deviation, IACUC: Institutional Animal Care and Use Committee, KCDC: Korea Centers for Disease Control and Prevention, KIT: Korea Institute of Toxicology, KLH: Keyhole limpet hemocyanin, LD: Lactation day, MMAD: Mass median aerodynamic diameter, OECD: Organization for Economic Co-operation and Development, PHMG-P: Polyhexamethylene guanidine phosphate, PND: Postnatal day, SD: Sprague-Dawley, T4: Thyroxine, TSH: Thyroidstimulating hormone

\section{Declarations}

\section{ACKNOWLEDGMENTS}

The authors thank the technical staff of the Developmental and Reproductive Toxicology Research Group at Korea Institute of Toxicology for their technical assistance.

\section{FUNDING}

This work was supported by the Ministry of Environment, Republic of Korea [grant number 2016001360006].

\section{Availability of data and materials}

The relevant datasets supporting the conclusions of this article are included within the article, and all datasets used and analyzed during the current study are available from the corresponding author on reasonable request.

\section{Authors' contributions}

JL, SJC, JSJ, KL and WJY conceived and designed the present study. SYK and SHL conducted the animal experiments, WK and JWC conducted the microscopic observation, and EMK conducted the immunological analysis. SJC and SHL established exposure condition and performed particle exposure and characterization. JL, YJY, SYN, EJJ, SJL and SKB interpreted the data and JL wrote the manuscript. All authors reviewed and approved the final manuscript.

\section{Ethics approval}

All animal protocols were prepared in accordance with the Animal Protection Act of Korea and Guide for the Care and Use of Laboratory Animals published by the Institute for Laboratory Animal Research (ILAR). This animal study was approved by the Institutional Animal Care and Use Committee (IACUC) of KIT.

\section{Competing interests}

The authors declare that they have no competing interests. 


\section{CONSENT FOR PUBLICATION}

Not applicable

\section{CONSENT TO PARTICIPATE}

Not applicable

\section{References}

1. Aleshina EY, Yudanova T, Skokova I. Production and properties of polyvinyl alcohol spinning solutions containing protease $C$ and polyhexamethylene guanidine. Fibre Chemistry. 2001;33 6:421-3.

2. Oule MK, Azinwi R, Bernier A-M, Kablan T, Maupertuis A-M, Mauler S, et al. Polyhexamethylene guanidine hydrochloride-based disinfectant: a novel tool to fight meticillin-resistant Staphylococcus aureus and nosocomial infections. Journal of medical microbiology. 2008;57 12:1523-8.

3. Oule MK, Quinn K, Dickman M, Bernier A-M, Rondeau S, De Moissac D, et al. Akwaton, polyhexamethyleneguanidine hydrochloride-based sporicidal disinfectant: a novel tool to fight bacterial spores and nosocomial infections. Journal of medical microbiology. 2012;61 10:1421-7.

4. Park E-J, Park S-J, Kim S, Lee K, Chang J. Lung fibroblasts may play an important role in clearing apoptotic bodies of bronchial epithelial cells generated by exposure to PHMG-P-containing solution. Toxicology letters. 2018;286:108-19.

5. Song J, Jung KJ, Yoon S-j, Lee K, Kim B. Polyhexamethyleneguanidine phosphate induces cytotoxicity through disruption of membrane integrity. Toxicology. 2019;414:35-44.

6. Paek D, Koh Y, Park D-U, Cheong H-K, Do K-H, Lim C-M, et al. Nationwide study of humidifier disinfectant lung injury in South Korea, 1994-2011. Incidence and dose-response relationships. Annals of the American Thoracic Society. 2015;12 12:1813-21.

7. Park J-H, Kim HJ, Kwon G-Y, Gwack J, Park Y-J, Youn S-K, et al. Humidifier disinfectants are a cause of lung injury among adults in South Korea: a community-based case-control study. PLoS One. 2016;11 3:e0151849.

8. Kim HJ, Lee M-S, Hong S-B, Huh JW, Do K-H, Jang SJ, et al. A cluster of lung injury cases associated with home humidifier use: an epidemiological investigation. Thorax. 2014;69 8:703-8; doi: 10.1136/thoraxjnl2013-204132. https://thorax.bmj.com/content/thoraxjnl/69/8/703.full.pdf.

9. Song JA, Park H-J, Yang M-J, Jung KJ, Yang H-S, Song C-W, et al. Polyhexamethyleneguanidine phosphate induces severe lung inflammation, fibrosis, and thymic atrophy. Food and chemical toxicology. 2014;69:26775.

10. KEITI: Supporting portal site for humidifier disinfectant victim. https://www.healthrelief.or.kr/home/content/stats01/view.do\# Accessed July 07, 2020.

11. Choi H-Y, Lee Y-H, Lim C-H, Kim Y-S, Lee I-S, Jo J-M, et al. Assessment of respiratory and systemic toxicity of Benzalkonium chloride following a 14-day inhalation study in rats. Particle and fibre toxicology. 2020;17 1:5.

12. Lee J-H, Kim Y-H, Kwon J-H: Fatal misuse of humidifier disinfectants in Korea: importance of screening risk assessment and implications for management of chemicals in consumer products. ACS Publications; 2012. 
13. Park D-U, Ryu S-H, Lim H-K, Kim S-K, Choi Y-Y, Ahn J-J, et al. Types of household humidifier disinfectant and associated risk of lung injury (HDLI) in South Korea. Science of the Total Environment. 2017;596:53-60.

14. Kim HR, Lee K, Park CW, Song JA, Park YJ, Chung KH. Polyhexamethylene guanidine phosphate aerosol particles induce pulmonary inflammatory and fibrotic responses. Archives of toxicology. 2016;90 3:617-32.

15. Song J, Kim W, Kim Y-B, Kim B, Lee K. Time course of polyhexamethyleneguanidine phosphate-induced lung inflammation and fibrosis in mice. Toxicology and applied pharmacology. 2018;345:94-102.

16. Lim C, Park S, Park J, Ko J, Lee DW, Hwang DS. Probing nanomechanical interaction at the interface between biological membrane and potentially toxic chemical. Journal of hazardous materials. 2018;353:271-9.

17. Kim HR, Da Young Shin KHC. A review of current studies on cellular and molecular mechanisms underlying pulmonary fibrosis induced by chemicals. Environmental health and toxicology. 2018;33 3.

18. Yang H-J, Kim H-J, Yu J, Lee E, Jung Y-H, Kim H-Y, et al. Inhalation toxicity of humidifier disinfectants as a risk factor of children's interstitial lung disease in Korea: a case-control study. PloS one. 2013;8 6.

19. Yoon J, Cho H-J, Lee E, Choi YJ, Kim Y-H, Lee JL, et al. Rate of humidifier and humidifier disinfectant usage in Korean children: A nationwide epidemiologic study. Environmental research. 2017;155:60-3.

20. Lee J, Jeong J-S, Kim SY, Im W-J, Shin Y-J, Lee K, et al. Reproductive and developmental toxicity screening of polyhexamethylene guanidine phosphate by oral gavage in rats. Regulatory Toxicology and Pharmacology. 2019;108:104440.

21. Lee J, Choi S-J, Jeong J-S, Kim SY, Lee S-H, Yang MJ, et al. A humidifier disinfectant biocide, polyhexamethylene guanidine phosphate, inhalation exposure during pregnancy induced toxicities in rats. Journal of Hazardous Materials. 2021;404:124007; doi: https://doi.org/10.1016/j.jhazmat.2020.124007. http://www.sciencedirect.com/science/article/pii/S030438942031997X.

22. OECD. OECD gudieline for the testing of chemicals No. 443: Extended one-generatoin reproductive toxicity study. 2018.

23. Council NR. Guide for the care and use of laboratory animals. National Academies Press; 2010.

24. OECD. Test No. 412: Subacute Inhalation Toxicity: 28-Day Study. 2018.

25. Park S, Lee K, Lee EJ, Lee SY, In KH, Kim H-K, et al. Humidifier disinfectant-associated interstitial lung disease in an animal model induced by polyhexamethylene guanidine aerosol. American journal of respiratory and critical care medicine. 2014;190 6:706-8.

26. Moser VC. Applications of a Neurobehavioral Screening Battery. Journal of the American College of Toxicology. 1991;10 6:661-9; doi: 10.3109/10915819109078658. https://doi.org/10.3109/10915819109078658.

27. Pierce RC, Kalivas PW. Locomotor behavior. Current protocols in neuroscience. 2007;40 1:8.1. -8.1. 9.

28. Tyl RW, Crofton K, Moretto A, Moser V, Sheets LP, Sobotka TJ. Identification and interpretation of developmental neurotoxicity effects: a report from the ILSI Research Foundation/Risk Science Institute expert working group on neurodevelopmental endpoints. Neurotoxicology and teratology. 2008;30 4:349-81.

29. OECD. Guidance document supporting OECD test guideline 443 on the extended one-generation reproductive toxicity test. 2013.

30. OECD. Test No. 426: Developmental Neurotoxicity Study. 2007.

31. Crofton KM, Foss JA, Hass U, Jensen KF, Levin ED, Parker SP. Undertaking positive control studies as part of developmental neurotoxicity testing: a report from the ILSI Research Foundation/Risk Science Institute expert

Page 27/32 
working group on neurodevelopmental endpoints. Neurotoxicology and teratology. 2008;30 4:266-87.

32. Lee J, Jeong J-S, Kim SY, Park M-K, Choi S-D, Kim U-J, et al. Titanium dioxide nanoparticles oral exposure to pregnant rats and its distribution. Particle and Fibre Toxicology. 2019;16 1:31.

33. Kim HR, Chung KH. The role of NF-KB signaling pathway in polyhexamethylene guanidine phosphate induced inflammatory response in mouse macrophage RAW264. 7 cells. Toxicology letters. 2015;233 2:148-55.

34. Song M-K, Kim DI, Lee K. Time-course transcriptomic alterations reflect the pathophysiology of polyhexamethylene guanidine phosphate-induced lung injury in rats. Inhalation Toxicology. 2019;31 1314:457-67.

35. Hood RD. Developmental and reproductive toxicology: a practical approach. CRC press; 2011.

36. OECD. Guidance document on mammalian reproductive toxicity testing and assessment. 2008. http://www.oecd.org/officialdocuments/publicdisplaydocumentpdf/? cote=env/jm/mono(2008)16\&doclanguage=en.

37. Carney EW, Zablotny CL, Marty MS, Crissman JW, Anderson P, Woolhiser M, et al. The effects of feed restriction during in Utero and postnatal development in rats. Toxicological Sciences. 2004;82 1:237-49; doi: 10.1093/toxsci/kfh249. https://www.scopus.com/inward/record.uri?eid=2-s2.08444241855\&doi=10.1093\%2ftoxsci\%2fkfh249\&partnerlD=40\&md5=4b6db6aacd471d5f0e84f9b4dc8fa1a1.

38. Griggio MA, Luz J, Gorgulho AA, Sucasas CM. The Influence of Food Restriction During Different Periods of Pregnancy. International Journal of Food Sciences and Nutrition. 1997;48 2:129-34; doi:

10.3109/09637489709006972. https://doi.org/10.3109/09637489709006972.

39. ICH. ICH S5(R3): Detection of reproductive and developmental toxicity for human pharmaceuticals. 2020. https://database.ich.org/sites/default/files/S5-R3_Step4_Guideline_2020_0218_1.pdf.

40. Barker DJ, Eriksson JG, Forsén T, Osmond C. Fetal origins of adult disease: strength of effects and biological basis. International journal of epidemiology. 2002;31 6:1235-9.

41. Walsh K, McCormack CA, Webster R, Pinto A, Lee S, Feng T, et al. Maternal prenatal stress phenotypes associate with fetal neurodevelopment and birth outcomes. Proceedings of the National Academy of Sciences. 2019;116 48:23996-4005.

42. Cao-Lei L, De Rooij S, King S, Matthews S, Metz G, Roseboom T, et al. Prenatal stress and epigenetics. Neuroscience \& Biobehavioral Reviews. 2017.

43. Dunkel Schetter C, Lobel M. Pregnancy and birth outcomes: A multilevel analysis of prenatal maternal stress and birth weight. 2012.

44. Hartwig IR, Sly PD, Schmidt LA, van Lieshout RJ, Bienenstock J, Holt PG, et al. Prenatal adverse life events increase the risk for atopic diseases in children, which is enhanced in the absence of a maternal atopic predisposition. Journal of allergy and clinical immunology. 2014;134 1:160-9. e7.

45. Hack M, Taylor HG, Drotar D, Schluchter M, Cartar L, Andreias L, et al. Chronic conditions, functional limitations, and special health care needs of school-aged children born with extremely low-birth-weight in the 1990s. Jama. 2005;294 3:318-25.

46. Barker DJ, Godfrey KM, Gluckman PD, Harding JE, Owens JA, Robinson JS. Fetal nutrition and cardiovascular disease in adult life. The Lancet. 1993;341 8850:938-41.

47. Park D-U, Friesen MC, Roh H-S, Choi Y-Y, Ahn J-J, Lim H-K, et al. Estimating retrospective exposure of household humidifier disinfectants. Indoor air. 2015;25 6:631-40. 
48. Park D, Leem J, Lee K, Lim H, Choi Y, Ahn J-J, et al. Exposure characteristics of familial cases of lung injury associated with the use of humidifier disinfectants. Environmental Health. 2014;13 1:70.

49. LoMauro A, Aliverti A. Respiratory physiology of pregnancy. Physiology masterclass. 2015;11 4:297-301; doi: 10.1183/20734735.008615. https://breathe.ersjournals.com/content/breathe/11/4/297.full.pdf.

50. Park D-U, Ryu S-H, Roh H-S, Lee E, Cho H-J, Yoon J, et al. Association of high-level humidifier disinfectant exposure with lung injury in preschool children. Science of the Total Environment. 2018;616:855-62.

51. Ryu SH, Park DU, Lee E, Park S, Lee SY, Jung S, et al. Humidifier disinfectant and use characteristics associated with lung injury in Korea. Indoor air. 2019;29 5:735-47.

\section{Figures}

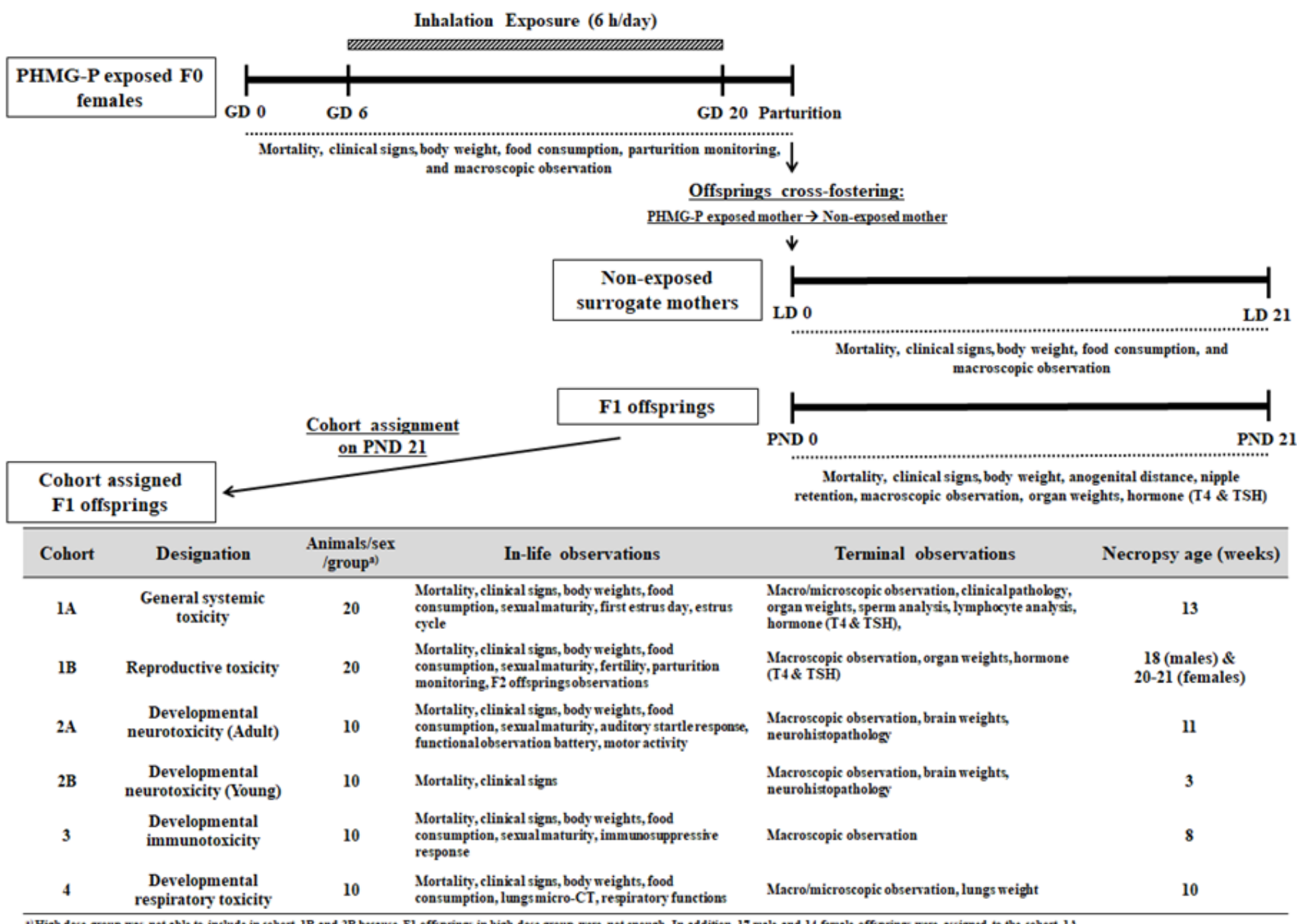

"High dose group was not able to include in cohort 1B and 2B because F1 offiprings in high dose group were not enough. In addition, 17 male and 14 female offsprings were assigned to the cohort $1 \mathrm{~A}$.

\section{Figure 1}

Schematic representation of the study design. 

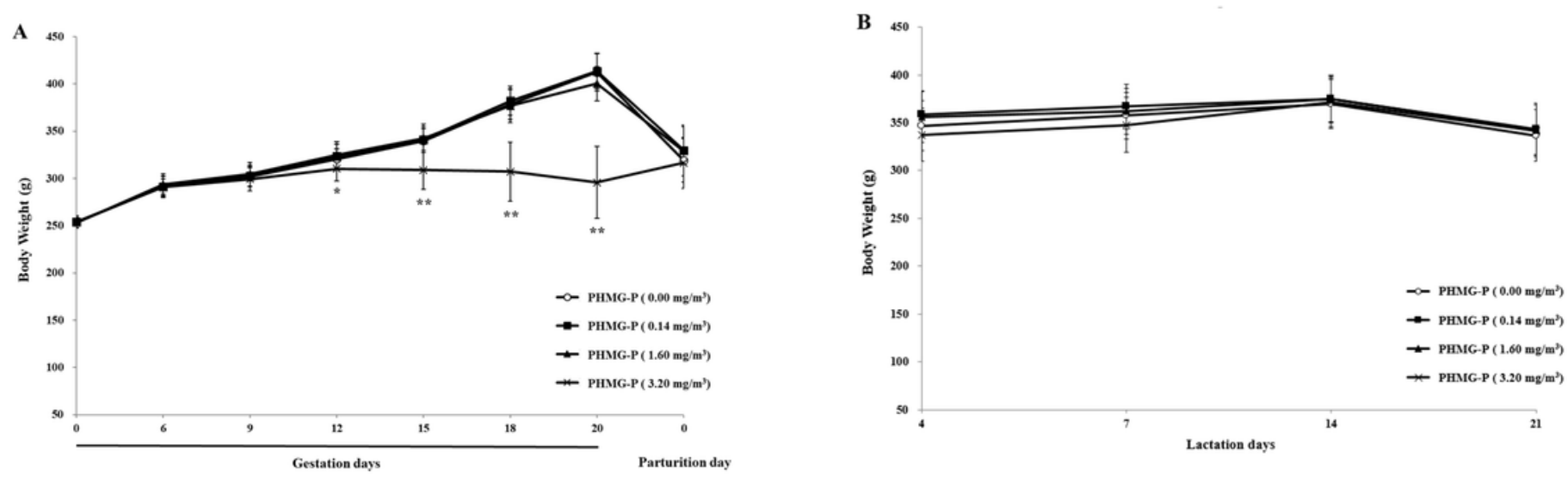

\section{Figure 2}

Mean body weight of (A) polyhexamethylene guanidine phosphate (PHMG-P)-exposed F0 female rats and (B) non-exposed surrogate mothers. ${ }^{*} p<0.05$ and ${ }^{* *} p<0.01$, compared with the control group.
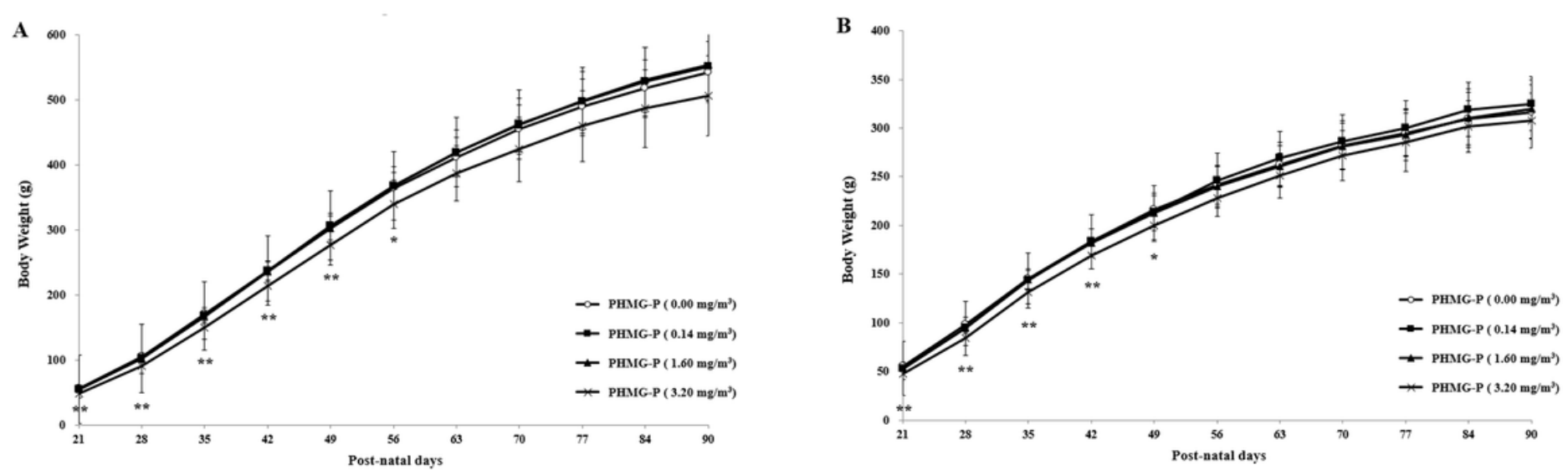

\section{Figure 3}

Mean body weight of prenatally polyhexamethylene guanidine phosphate (PHMG-P)-exposed F1 (A) male and (B) female offspring in cohort $1 \mathrm{~A}$ after weaning. ${ }^{*} \mathrm{p}<0.05$ and ${ }^{* *} \mathrm{p}<0.01$, compared with the control group. 

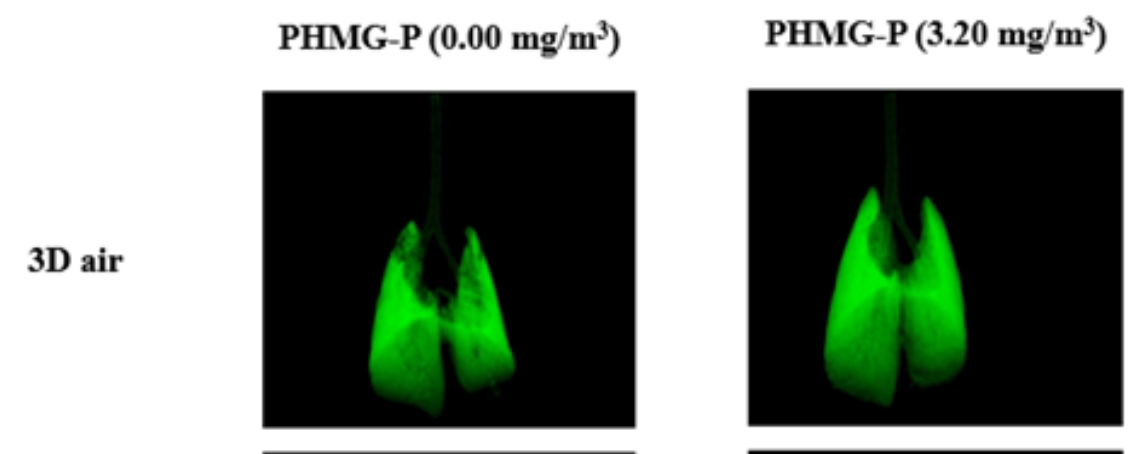

$3 D$ tissue
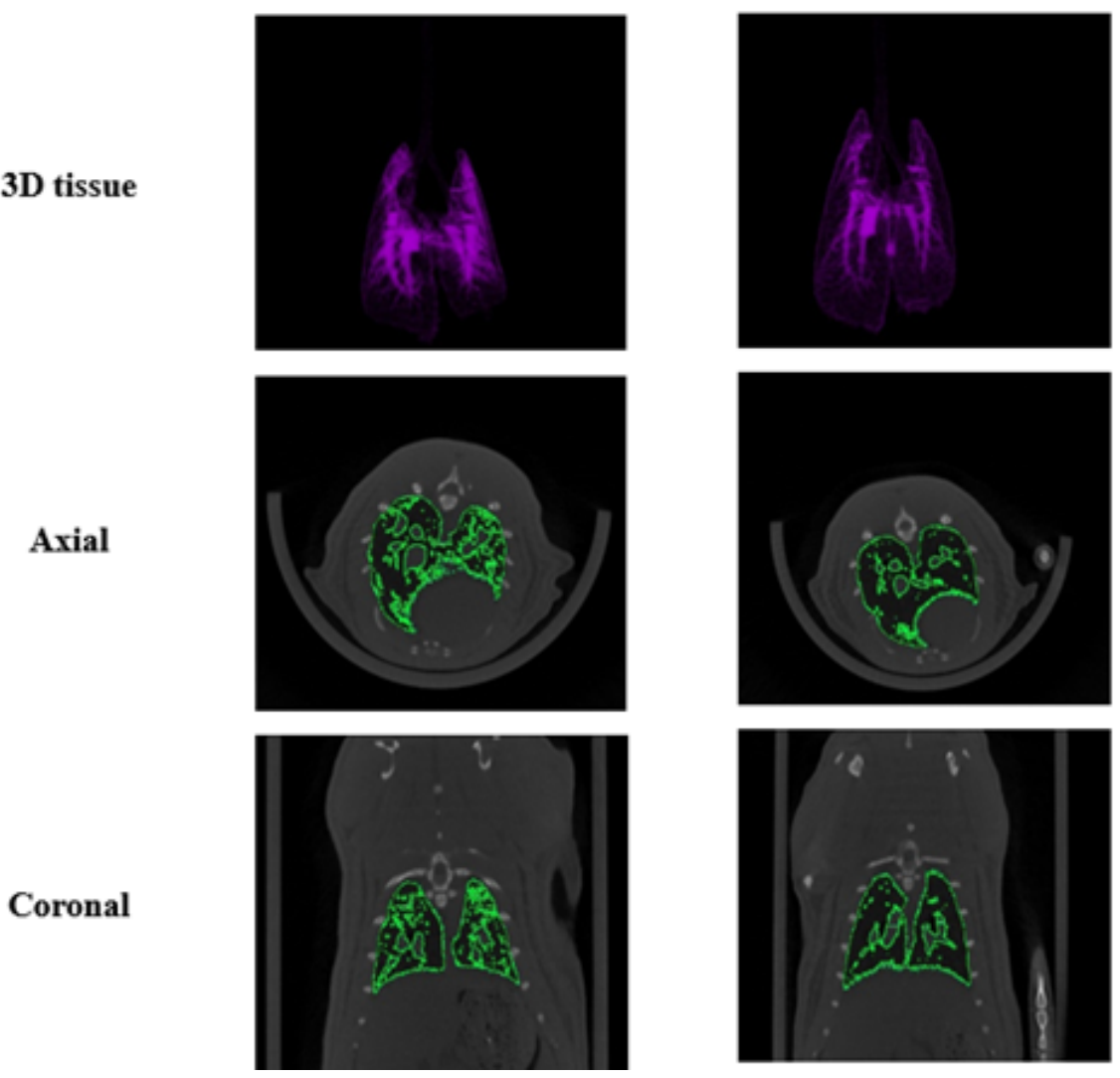

\section{Figure 4}

Micro-CT images of lungs of prenatally polyhexamethylene guanidine phosphate (PHMG-P)-exposed F1 offspring before necropsy (at approximately 10 weeks of age) in cohort 4. 

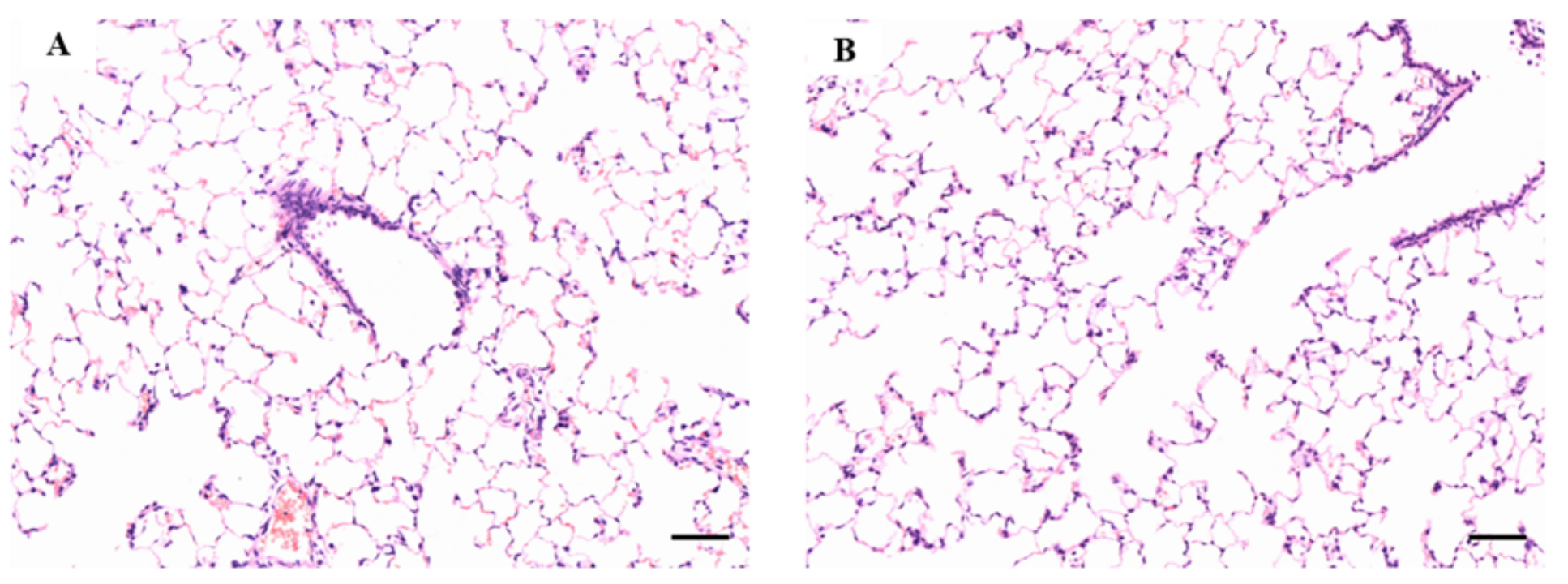

\section{Figure 5}

Microscopic observation of lungs of prenatally polyhexamethylene guanidine phosphate (PHMG-P)-exposed F1 offspring at (A) control group and (B) high (3.2 mg/m3)- concentration group in cohort 4; scale bars, $100 \mu \mathrm{m}$. 